Copyright (C) 2014 by Academic Publishing House Researcher

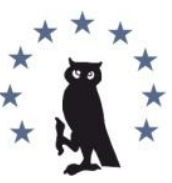

Published in the Russian Federation

European Researcher

Has been issued since 2010.

ISSN 2219-8229

E-ISSN 2224-0136

Vol. 84, No. 10-1, pp. 1765-1775, 2014

DOI: $10.13187 / \mathrm{er} .2014 .84 .1765$

www.erjournal.ru

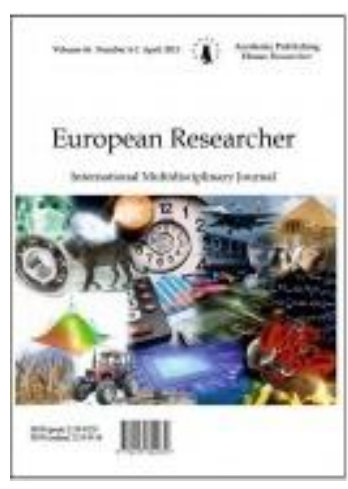

UDC 338.12.017

\title{
The Perspectives of Tourism Development in Kazakhstan
}

Almagul Sh. Nurgalieva

Academy of Imageology, Kazakhstan

Vice-chancellor for education and science

PhD (Economy), Associated Professor

010000, Kazakhstan, Astana city, Tarkhan-Gastello street, 1, flat 6

E-mail: nurgalieva_as@mail.ru

\section{Abstract}

In the article the problem of tourism in Kazakhstan has been researched out, analyzed the main tourist indicators in tourism with the orientation for external tourism, showed the results of experts' due to facts restraining tourism development in the country. The important and perspective directions of tourism development have been determined.

Keywords: tourism; internal tourism; tourism perspectives; tourist development; competitive perspectives; tourist products; customers opportunity; Silk way.

\section{Введение}

Туристская индустрия - это отрасль с широкими возможностями и высокой рентабельностью, поскольку туризм носит глобальный характер и обладает очень сильным и стабильным потенциалом роста. Индустрия туризма привлекает инвестиции на высоком уровне (как в недавних примерах в Турции, Дубае, Малайзии, Канаде, Южной Африке и т.д.). При условии устойчивого развития туризм имеет тенденцию к росту при условии высокой ставки налога на добавленную стоимость и относительно низкой импортной составляющей. Туристская индустрия прямо и косвенно создает рабочие места и обеспечивает огромный приток иностранной валюты $[1,13]$. Отрасль может развиваться быстрыми темпами, что было недавно показано на примере многих конкурентоспособных с точки зрения туризма стран, которых еще каких-то 10 или 15 лет назад не было на глобальной карте туризма. В связи с этим актуально рассмотрение проблемы развития въездного туризма в Казахстане и занятие устойчивых позиций на международном рынке.

\section{Анализ развития туризма в Казахстане}

Экономическое влияние туризма на экономику страны проявляется через показатели денежных потоков, направленных из страны и в страну, которые генерируются туристским экспортом и импортом. Большая часть доходов от экспорта туристских услуг поступает от прибывающих иностранных туристов, а также от продажи билетов на отечественный транспорт и другие услуги в стране пребывания. Туристский импорт страны составляют 
деньги, потраченные ее гражданами во время зарубежных поездок, оплата ими транспортных расходов и других услуг в странах пребывания, а также оплата дивидендов иностранным инвесторам индустрии туризма. Разница между доходом страны от экспорта туристских услуг и стоимостью импорта туристских услуг представляет туристский платежный баланс, который может быть отрицательным (дефицит) и положительным [2].

В случае большого дефицита происходит утечка денежных ресурсов из страны. Поэтому не только малые страны, но и такие промышленно развитые государства, как США, Англия и Германия, стремятся к увеличению доходов от туризма и прилагают серьезные усилия для привлечения в страну иностранных туристов.

В 2011 году туристские фирмы Казахстана обслужили 36,1 тыс. человек, въехавших в Казахстан. При этом в сравнении с 2009 годом рост на 3 \%, тогда как по сравнению с 2008 г. и 2010 г. происходит снижение на 15,1 и 18,8 \% соответственно [3].

Исходя из данных численности обслуженных посетителей туристскими фирмами, можно отметить положительную динамику за 2009, 2010, 2011, 2012, 2013 гг. табл. 1

\section{Динамика численности обслуженных посетителей туристскими фирмами (чел.)}

\begin{tabular}{|l|l|l|}
\hline годы & Январь-декабрь & Рост,+ снижение-, в \% \\
\hline 2007 & 541930 & - \\
\hline 2008 & 473947 & $-14,3$ \\
\hline 2009 & 347413 & $-36,42$ \\
\hline 2010 & 459337 & $+24,4$ \\
\hline 2011 & 601521 & $+23,6$ \\
\hline 2012 & 702423 & $+16,7$ \\
\hline 2013 & 745198 & $+06,0$ \\
\hline
\end{tabular}

Опираясь на официальные статистические данные 2007-2011 годов, можно предположить, что динамика прироста количества туристов сохранится.

Более 50 \% туристов, приезжавших в Казахстан в 2011 году, составили туристы из Германии, Китая. Среди стран СНГ наибольшую долю составляют туристы из России $63,6 \%$.

География туристов, посещающих Казахстан в последнее время, заметно расширилась, однако цель посещения страны для большинства туристов - отнюдь не отдых. Значительная часть въезжающих в страну иностранцев прибывают с деловой целью [4].

Сегодня Казахстан не выглядит привлекательным в глазах иностранных граждан как место проведения отпуска, что связано с рядом объективных причин. Во-первых, это информационный «голод»: хотя в стране есть множество уникальных и красивейших мест, они не пользуются популярностью у иностранных туристов из-за того, что о них просто не знают. Во-вторых, в стране слабо развита индустрия отдыха.

Безусловно, стопроцентной гарантии на рынке туристских услуг не существует. Даже у самых опытных туристских агентств могут быть непредвиденные обстоятельства из-за нарушения обязательств авиакомпаниями, гостиницами или просто из-за заболевшего водителя автобуса, не встретившего рейс. Однако все эти сложности, с которыми сталкиваются туристские агентства, с лихвой окупятся, если наладить грамотную, профессиональную работу.

Согласно данным Агентства по статистике Республики Казахстан, в 2011 году в Казахстане было официально зарегистрировано 1602 туристических фирм и организаций, большинство из которых (855) действуют в Алматы.

\section{Результаты экспертного опроса}

Основу туристских компаний составляют малые предприятия с численностью до 50 человек (93 \%), 6 \% - средние организации (от 51 до 250 человек). Крупных туристских организаций только восемь. Среди них можно назвать такие, как Kazakhstan Travel 
International, Central Asian Corporation, «Отрар Авиа», ТОО «Турагентство Шелковый путь» и др. [5]

Однако исходя из данных экспертного опроса данные Агентства по статистике не полные, и только в Алматы около 1 ооо туристских компаний.

Менее трети респондентов (30 \%) сообщили о неизменности объемов реализации услуг во втором квартале 2011 года по сравнению с I кварталом, каждый второй (50 \%) - об увеличении и $20 \%$ - об уменьшении. Это свидетельствует о стабильности в сфере предоставления туристских услуг и даже о некотором увеличении рынка, поскольку более половины участников рынка заявили об увеличении объема предоставляемых услуг.

Большинство руководителей туристских фирм полагают, что основным фактором, ограничивающим рост объема услуг, является увеличение конкуренции на рынке. Это подтверждают данные экспертного опроса о количестве туристских агентств в республике. Из других внешних факторов наибольшее число опрашиваемых (27 \%) указали на снижение покупательского спроса. Эта ситуация, скорее всего, связана с тем, что резко возросли цены на авиабилеты, в связи, с чем часть потребителей предпочла «переждать» это повышение (см. график 1).

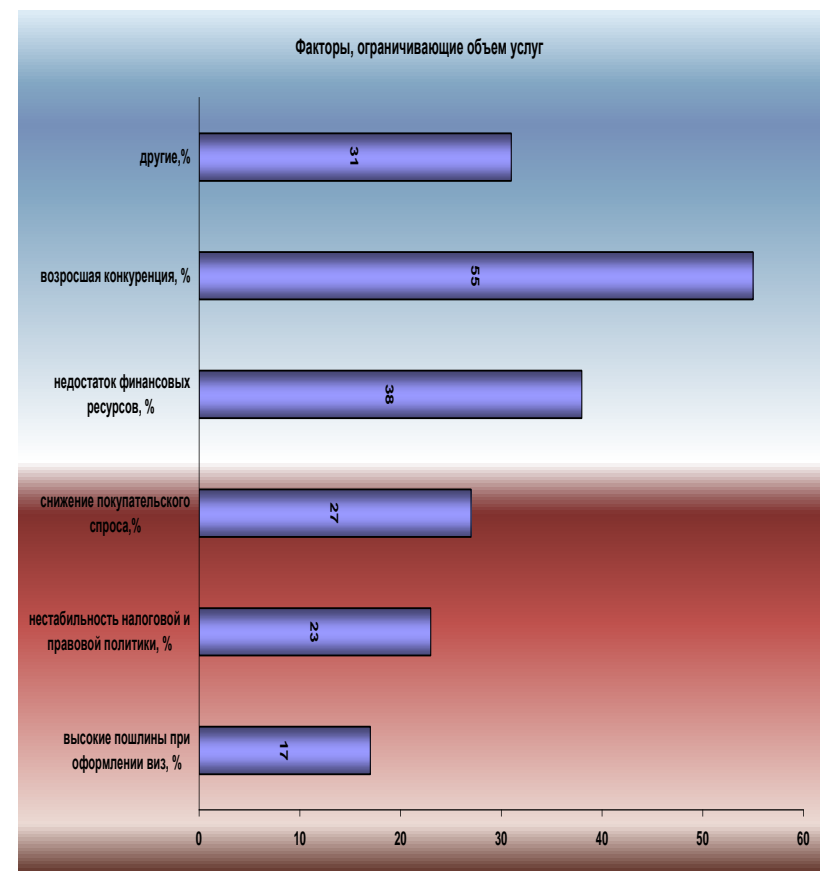

18 \% руководителей сообщили, что ограничений для роста объемов услуг нет.

Согласно данным опроса, большинство руководителей туристских агентств оценивают уровень конкуренции на рынке как высокий. По мнению $68 \%$ руководителей туристских фирм, основным фактором, усиливающим конкуренцию, является проникновение на рынки услуг новых туристских организаций. $37 \%$ опрошенных полагают, что конкуренция в отрасли увеличивается в связи с агрессивной рекламной компанией ряда туристских агентств (см. график 2).

Кроме того, большая часть руководителей положительно оценивает перспективы развития туризма в краткосрочный период. Так, 50 \% предпринимателей полагают, что доходы от реализации туристских услуг увеличатся, и только $7 \%$, что доходы от продажи услуг уменьшатся.

Очевидно, что для развития въездного туризма в стране необходимо приложить усилия не только самим туристским агентствам, но и решать эту проблему на государственном уровне, так как развитие въездного туризма благоприятно отразится не только на государственной казне, но и на формировании общего положительного имиджа страны в глазах мировой общественности.

Изучение важнейших зарубежных рынков позволило сделать следующие выводы: 
- Россия представляет собой важнейший зарубежный рынок для казахстанского туризма по причине своих размеров, покупательной способности, общей с Казахстаном истории и положительного мнения о туристских ресурсах Казахстана. Подсчитано, что россияне могут совершать более миллиона поездок - цифра, возросшая более чем в 5 раз за менее чем 10 лет;

- Китай - быстро растущий рынок для Казахстана, однако следует учитывать расстояние до самых богатых и густонаселенных районов Китая и большое количество конкурентных предложений для китайских туристов. Но поскольку сегодня из Китая совершаются около 25 тыс. поездок, есть основания полагать, что данный быстро растущий рынок, который также является соседом Казахстана, может достигнуть уровня полумиллиона посещений;

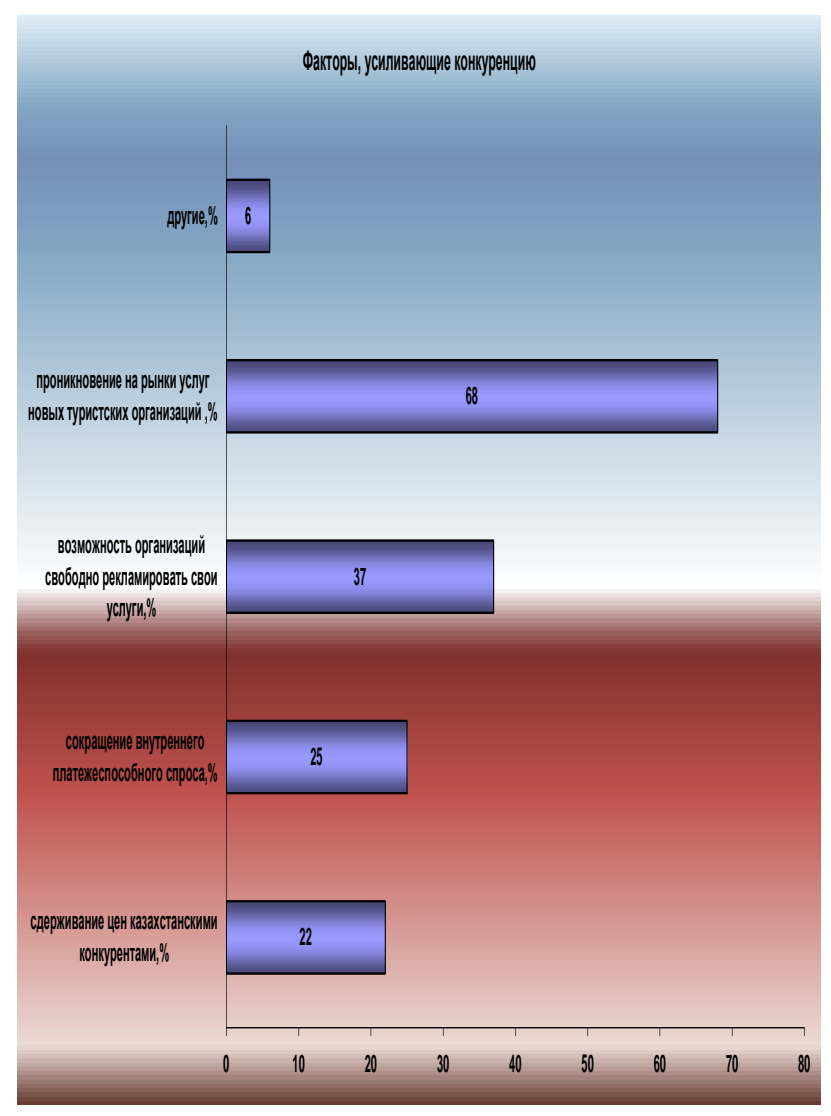

- Европа - один из важнейших рынков для Казахстана, дающий около 150 тыс. посещений, в основном, это деловые поездки, поездки культурологического характера и некоторые продукты, представляющие особый интерес (активный и приключенческий отдых). При надлежащем развитии в следующий период можно смело предположить, что число европейских туристов, посещающих Казахстан, может быть в 4-5 раз больше;

- Анализ показал, что потенциальное предложение туристских продуктов Казахстана имеет мало возможностей для привлечения стран Ближнего и Среднего Востока (за исключением Турции). Ожидается, что, несмотря на то, что абсолютные показатели для таких рынков возрастут в несколько раз, они не догонят показатели для региональных рынков;

- Можно ожидать, что оставшаяся доля прочих рынков может составить, в конечном итоге, 10 \% от общей доли зарубежных рынков.

Большинство экспертов уверено, что Казахстан далеко не полностью использует свои возможности по развитию туризма, а между тем обширный международный опыт показывает, что индустрия туризма является одной из самых перспективных отраслей экономики страны. 
Туризм реально претендует на то, чтобы стать третьей по доходности индустриальной отраслью в Казахстане. Сегодня, по оценкам экспертов, одним из основных сдерживающих факторов развития туризма является отсутствие в Казахстане необходимой инфраструктуры. Также необходимо признать, что в последние годы было много сделано в этом направлении, однако развитие туристской отрасли связано со значительными инвестициями [5].

На основе проведенного Агентством РК по туризму и спорту анализа с учетом рекомендаций ЮНВТО было выделено два базовых компонента казахстанского турпродукта: культурный туризм на Шелковом пути (паломнический и традиционный) и тесно связанный с ним эко-приключенческий туризм (сафари, рафтинг, орнитологический, треккинг, альпинизм, охота, рыбалка). В этом отношении были выделены регионы, имеющие ресурсы для эко-приключенческого туризма, через которые пролегает маршрут Шелкового пути: Алматинская, Жамбылская, Южно-Казахстанская, ВосточноКазахстанская, Акмолинская области.

Кроме того, высокой степенью привлекательности, доступностью территории в плане организации туризма характеризуются государственные национальные природные парки (ГНПП): ГНПП "Иле-Алатау", ГНПП "Алтын-Емель" (Алматинская область), ГНПП "АксуДжабаглы" (Южно-Казахстанская область), ГНПП "Баян-Аул" (Павлодарская область), ГНПП "Каркаралинский" (Карагандинская область), ГНПП "Бурабай" и "Кокшетау" (Акмолинская область).

По мнению экспертов Агентства по туризму, отличительной чертой казахстанского туристского продукта является сезонность его характера, что требует принятия определенных мер и развития альтернативных видов туризма в несезон. Инфраструктура, соответствующая вышеуказанным сегментам, имеет определенные требования. Это должны быть простые, относительно недорогие некрупные (в пределах 25-100 мест) объекты размещения (стационарные и временные), расположенные на туристских маршрутах в экологически чистых местах, рассчитанные на пребывание клиентов на одном месте в течение 2-3 дней.

Внутренний туристский рынок в большинстве развитых в туристском плане стран приносит от 30 \% до 50 \% общего дохода от туризма. В этом отношении Казахстан имеет хорошие перспективы. В то же время следует отметить, что сегодня внутренний туризм в основном является стихийным, неорганизованным. Исключение составляет деятельность немногих курортов, санаториев и туристских баз. Из-за отсутствия должного внимания к этому виду туризма бюджет государства недополучает огромную сумму, продолжает разрушаться инфраструктура, наносится серьезный ущерб экологическому состоянию природных, культурных и исторических памятников [6].

Нами проведена экспертная оценка Мастер-плана развития туризма в одной из областей Казахстана. Экспертной группой использовался синтезис из нескольких методов оценки - сравнительный анализ кластеров, SWOT анализ, NPD (развитие нового продукта) моделирование, экономическую оценка реализации Мастер-плана, метод "Ситуационного анализа", метод "Примеров лучших практик", а также метод "Анализа систем и процессов" для спецификации нужд организации кластера, методы анализа "Аналогичного поведения", "Учета аттрибутов" и "Управление внутренними инновационными предложениями" - как теоритические модели и методы развития инновационных решений. Для общей оценки возможностей внедрения Мастер-плана использовался комплексный метод "Управления качества инновационных процессов", как наиболее подходящий в данном случае. Также, для ознакомления с реальной ситуацией по организации развития туристского кластера в области на 2009-2011 годы в апреле-мае 2011 года было проведено экспертное посещение и ознакомление с большинством из указанных в Мастер-плане объектами, включенными в разработанную модель развития кластера.

В связи с недостаточным или неполным количеством и качеством точных данных и детально разработанных факторов влияния, указанных в Мастер-плане не было возможным использование статистических и квантитативных методов и моделей кластерного анализа, например, индекс Дейвиса-Болдвина или индекс Данна для внутреннего анализа кластеров и измерение Ранда или индекс Джакарда для внешнего анализа.

SWOT анализ: 


\section{Плюсы (сильные стороны):}

План объективно охватывает основные группы предполагаемых участников кластера;

Дана начальная оценка экономической эффективности внедрения кластера;

Указаны главные факторы, как внутренние, так внешние, негативно влияющие на полноценное внедрение Мастер-плана.

Детально разработан план конкретных мероприятий, включенных в процесс развития туристского кластера в области на 2009-2011 годы

Минусы (слабые стороны):

Не учтено влияние на развитие кластера соседних и смежных территорий, особенно, города-столицы Астаны.

Не достаточно разработаны возможности и принципы взаимодействия между участниками кластера, а также возможные пути синергического взаимодействия с соседними территориями, например в развитии придорожного сервиса.

Слабая оценка деградирующего фактора влияния антропогенного фактора на зеленые природные территории и заповедники - нет оценки максимальной сохраняющей нагрузки на эти территории и внедрение возможных ограничений;

Нет оценки и предложений по ограничению конфликта между публичным и частным правом пользования - например, большинство водоёмов ограничено частными территориями и не доступно для общественного использования;

Дана неполная оценка целевого назначения входящего заграничного туризма большинство входящих туристов более заинтересованы в культурном, историческом или развлекательном туризме (например - сакральный туризм, исторические объекты и раскопки, казахские национальные традиции и церемонии, местные гастрономические особенности, спортивные мероприятия, игральные залы и развлечения) а не только посещение зеленых территорий.

План слабо акцентирует развитие новых, инновационных видов привлечения потоков входящего и местного туризма, вместо этого концентрируясь на использование старой, уже перегруженной инфраструктуры традиционных видов туризма.

Перспектива развития туристских кластеров в регионах

Современные тенденции в развитии туризма свидетельствуют о возрастании его влияния как на мировую экономику в целом, так и на экономику отдельных стран и регионов. Туризм представляет собой крупную сферу национального хозяйства, деятельность которой, с одной стороны, направлена на удовлетворение специфических потребностей, возникающих у населения во время путешествия и отдыха, а с другой - может обеспечить подъем экономики региона при создании эффективной системы регулирования данной отрасли.

Мировая практика свидетельствует, что туристский бизнес по доходности и динамичности развития уступает лишь добыче и переработке нефти. По данным Всемирной туристской организации он обеспечивает 10 \% оборота производственно-сервисного рынка, на его долю приходится 6 \% мирового валового национального продукта, 7 \% мировых инвестиций, 5 \% налоговых поступлений.

Помимо экономического мультипликативного эффекта туризм имеет и большое социальное значение, выраженное в рационализации использования свободного времени, заполнении его деятельностью, направленной на восстановление и расширенное воспроизводство духовных и физических сил человека. Его развитие усиливает ориентацию экономики на человеческие потребности.

Туризм сегодня - это важная отрасль экономики, которая во многих странах превратилась в быстро развивающуюся индустрию. В настоящее время каждое 7-е рабочее место в мире приходится на туристский бизнес. По прогнозам ВТО, к 2020 г. Количество международных туристских визитов составит 1,6 млрд., т.е. примерно в 3 раза превысит показатели 2000 г. Многие страны с высоким средним доходом на душу населения, такие как Швейцария, Австрия, Франция, Германия, Великобритания, Голландия и другие, значительную долю своего благосостояния построили на доходах от туризма.

Большое влияние как с экономической, а также с социальной точки зрения оказывает туризм и на регионы: благодаря развитию туризма создаются новые рабочие места, 
развиваются информационные и коммуникационные системы, повышается культура и грамотность местного населения и т.п.

Анализ современного развития туристских макро и микро кластеров во многих странах позволяет понять, что развитие туризма должно проводится по всем трем основным направлениям, указанным авторами данного документа - внутренний, въездной и выездной.

Эксперты согласны с тезисом, что развитие внутреннего туризма выгодно, т.к. приносит доход в местный бюджет от деятельности всего сектора туристского кластера гостиниц, транспорта, ресторанов, торговли, развлечения, а также не подвержен колебаниям социально-экономических и политических условий за пределами республики, но следует заметить, что внутренний (местный) туризм - это, со стороны экономической теории, всего-лишь передел заработанных финансовых ресурсов местных жителей от одного к другому в пределах региона. С глобальной точки зрения наиболее выгоден входящий вид туризма, так как он приносит в регион новые дополнительные финансовые ресурсы извне. При этом, возрос выездной туризм (означающий, по существу, вывоз капитала из страны), который по объему затрат превзошел валютные поступления от въездного туризма.

С переводом отрасли туризма на рыночные рельсы в Республики Казахстан в туристском секторе произошли коренные, но вместе с тем противоречивые изменения [7]. С одной стороны, турбизнес быстрее, чем другие отрасли адаптировался к рыночным условиям. Образовалось множество частных фирм, которые не только стали удовлетворять потребности граждан, прежде всего в выездном заграничном туризме, но и вовлекли в эту работу большое количество сотрудников, что оказало немалое позитивное влияние на рынок труда. Но в то же время развитие туризма в регионах осталось без серьезной государственной или муниципальной поддержки, что привело фактически к почти полному исчезновению социального туризма; шансы на выживание сохранили преимущественно коммерческие формы и виды туризма. Об этом можно судить также из содержания Мастерплана, так как в нем недостаточно уделено внимание таким видам и элементам туризма как сакральный туризм (захоронения, кладбища, церкви и.т.п.), культурный туризм (концерты, театры, показы мод, выставки искусств и.т.п.), исторический туризм (музеи, исторические раскопки, академические и этнографические коллекции и выставки и.т.п.), архитектурный туризм (выдающиеся архитектурные сооружения и памятники) а также гастрономический туризм (местные и традиционные блюда, рестораны и кафе с признанным качеством обслуживания). Пополнение туристских путеводителей вышеназванными объектами значительно повысит привлекательность области как высокоразвитого туристического региона в Республике Казахстан.

Основные направления развития туризма

Сравнивая ситуацию в области внутреннего туризма 10 лет назад и в настоящий период, можно смело заявить о возрождении внутреннего туризма. Что в целом вписывается в общемировую тенденцию, когда опасности, связанные с передвижением по миру (экстремизм, теракты), все больше склоняют потенциальных туристов остаться дома. Так, на прошедшем недавно в Москве семинаре национальных администраций туризма представитель Германии отметил резко возросшее количество путешествующих внутри страны и открытие таких направлений, как сельскохозяйственный туризм (посещение ферм и полей) [8].

Рекомендации и предложения:

1. Указать конкретные пути и виды снижения административных барьеров (затяжных процедур получения визы, высокой платы при ее получении, длительной регистрации иностранных туристов);

2. Применение научно обоснованных видов маркетинга (недостаток продвижения имиджа Казахстана на внешний рынок, отсутствие достаточного объёма рекламной информации о туристском потенциале Казахстана и Акмолинской области в частном, а также не хватка информационных стендов и центров обслуживания туристов);

3. Использование целевого финансирования отрасли туризма, желательно, в виде направленного программного финансирования или на конкурсной основе реализации приоритетных проектов; 
4. Разработать отдельный план по уменьшению сезонного характера большинства видов туризма;

5. Организовать рабочую группу или институцию для координации внутриотраслевой и межведомственной деятельности по вопросам общего развития инфраструктуры туризма;

6. Провести программу по обучению кадров (проблема - отсутствие кадров квалифицированных специалистов туризма, недостаток экскурсоводов, инструкторов со знанием иностранного языка, а также истории);

7. Ввести льготное налогообложение и кредитование фирм, работающих или планирующих работу в приоритетных отраслях кластера;

8. Разработать и реализовать схему по обеспечению безопасности и страхования туристов;

9. Разработать план по обеспечению туристов качественным и безопасным общественным транспортом, начиная с пункта прибытия и заканчивая транспортом местного назначения, также разработать многолетний план по развитию качественных дорог к пунктам назначения;

10. Улучшить менеджмент и администрацию, как в самой туристской сфере, так и в смежных с ней отраслях;

11. Изучить, используя научно-обоснованные методы, международный спрос на туристские услуги, которые может предложить Акмолинская область, с учетом экономической эффективности проводимых мероприятий. Туроператоры области работают более чем с 20 странами мира, но при этом не участвуют во всемирных, международных туристских биржах и ярмарках, следовательно, рациональна организация совместных стендов продвигающий турпродукты под единой маркой, разработанной исключительно для туристского кластера Акмолинской области;

12. Организовать помощь туристским компаниям по созданию собственных Веб-сайтов для рекламы и привлечения клиентов из-за границы и индексирования гостиничных, ресторанных и транспортных возможностей во всемирных системах резервирования, например "booking.com", “eurobookers.com";

13. Разработать план мероприятий развития специфической инфраструктуры туризма (строительство и реконструкция гостиниц, мотелей, кемпингов, кафе, ресторанов, игорных залов, спортивных стадионов и комплексов, природных, этнографических и исторических комплексов, дорог, систем сбора мусора, систем оповешения и информации и др.).

Учитывая проведенную экспертизу и анализ составных частей разработанного Мастерплана авторы рекомендует принятие данного документа за основу дальнейшего развития туристского кластера в области.

Также в настоящее время наблюдается активное развитие гостиничного бизнеса. При этом, если с начала 90-х было закрыто или перепрофилировано около 60\% всех гостиниц, то за последние 3 года отмечается обратный процесс открытия новых гостиниц и гостевых домов. Наиболее динамично данный процесс прослеживается в ЩучинскоБоровской зоне, на юге и западе Казахстана, "где наконец-то начали строить гостиницы на 15-17 номеров, в основном работающих на принципе семейного бизнеса". Пока же очень дорогие гостиничные услуги для туристов обусловлены изначально неправильно выбранной ориентацией на клиентскую базу. Зачастую много гостиниц строится без точного экономического подсчета, просто ради вложения денег, и зачастую - для бизнес-аудитории, а необходимо строительство недорогих гостиниц так называемого эконом - или туристского класса. В такой гостинице можно обойтись без дорогих импортных отделочных материалов, из услуг предоставляя возможность сходить в ресторанчик, а также услуги связи и выход в интернет [9].

Внутренний туризм, нацеленный на свое население, является самым надежным способом развития туризма в Казахстане [10]. Это объясняется тем, что строительство туркомплексов для казахстанских туристов будет экономически окупаемо, так как свои туристы поедут отдыхать вне зависимости от политической ситуации вокруг Казахстана.

Казахстан практически неизвестен в мире как туристское направление, хотя его земли издавна обеспечивали связь между Китаем и Европой, будучи на протяжении столетий свидетелями многих исторических событий на участке Великого Шелкового пути. Создание привлекательного туристского имиджа Казахстана требует проведения соответствующего 
широкомасштабного комплекса мер [11]. Основными имиджевыми мероприятиями должны стать участие туристских фирм и агентств Казахстана в международных туристских выставках, ярмарках и конференциях, в том числе проводимых по линии ЮНВТО, а также организация подобных мероприятий на территории Республики Казахстан. Важно развивать конгрессный туризм, который будет способствовать превращению Казахстана в центр общественных и культурных событий Евразии.

Международное сотрудничество в туризме осуществляется посредством участия в разработке и реализации проектов ЮНЕСКО и ЮНВТО по Великому Шелковому пути, заключения двусторонних и многосторонних соглашений с иностранными государствами. Немаловажную роль в формировании туристского имиджа страны играет организация туристских информационных центров как в регионах республики, так и за рубежом [12]. Должное внимание следует уделить использованию практики взаимодействия туристских организаций с дипломатическими представительствами Казахстана за рубежом.

Необходимо издание и активное распространение за рубежом высококачественных полиграфических и аудиовизуальных рекламных материалов о Казахстане. Привлечению туристов в Казахстан будут способствовать краеведческие публикации, рекламноиздательская деятельность, в том числе туристских фирм и гостиниц. Особое внимание следует уделить использованию новейших информационных технологий, в том числе созданию WEB-сайтов туристских фирм Казахстана в сети интернет.

Созданию благоприятного туристского имиджа будет способствовать проведение в Казахстане различных культурных, спортивных и туристских мероприятий на международном уровне. Большое значение для формирования туристского имиджа Казахстана будет иметь упрощение порядка въезда, выезда и пребывания на территории республики иностранных граждан, визовых и таможенных процедур с введением в действие единой компьютеризированной системы учета. Созданию имиджа гостеприимной республики будут также способствовать изготовление и установка в местах, наиболее часто посещаемых туристами, информационных табло и надписей, дублирующих русский, казахский тексты латинской транскрипцией.

За последнее десятилетие значительно расширилась география путешествий казахстанцев, при этом маршруты Великого Шелкового пути традиционно привлекают огромный интерес во всем мире. Этот факт подтверждает включение казахстанской туристской ярмарки "KITF" в план мероприятий Всемирной туристской организации (UNWTO). Динамизм развития туристской ярмарки в значительной степени происходит благодаря общей прогрессирующей экономической ситуации и государственной политике Казахстана. В рамках "КITF" проходят презентации компаний, отдельных проектов, розыгрыши призов, конкурсы, шоу, семинары, клубные мероприятия и светские приемы.

\section{Выводы}

Туризм в целом оказывает три положительных эффекта на экономику государства: обеспечивает приток иностранной валюты, оказывает положительное влияние на такие экономические показатели, как платежный баланс и совокупный экспорт, и помогает увеличить занятость населения.

В последние годы в Европе наметилась четкая тенденция к развитию такой формы туризма, как посещение городов - городской туризм. Раньше поездки строго делились на деловые, для отдыха и лечения, религиозные и так далее. Но наши исследования показывают, что эти грани постепенно стираются. Сегодня приезжающий в деловую командировку человек может продлить пребывание, чтобы продолжить знакомство с достопримечательностями города или страны. То есть происходит объединение, смешивание целей визита, и во многих местах формируется концепция городского туризма. Например, на Мальдивах доходы от него составляют почти $84 \%$ внутреннего валового продукта. У нас - для сравнения - менее 0,1 \%. Но это не просто примитивное опустошение кошелька туриста - это целый сплав наук: психология, маркетинг, сервис, реклама, медицина, конкуренция. Мировой туризм учитывает все - от географических пристрастий потенциального путешественника до вида его любимой зубной щетки. И мировой туризм может расширяться за счет таких экзотических стран, где еще не было массового наплыва туристов. 
Основными конкурирующими направлениями для Казахстана являются страны Центральной Азии, в частности Узбекистан и Кыргызстан, это касается туристских продуктов, культуры, административных формальностей и низких цен, но также и Россия, Украина и Азербайджан.

По мнению ведущих туроператоров, основными барьерами на пути к дальнейшей популяризации Казахстана на международном рынке являются недостаток инвестиций в развитие, юридические и прочие административные барьеры (в особенности визовая система), не до конца разработанные туристские продукты и транспортные возможности, недостаток знаний, несоответствующий уровень рекламных материалов, недостаточное присутствие международных гостиничных сетей и плохое соотношение цены и качества. Многие природные объекты недоступны для неинформированных туристов.

Казахстану следует улучшать свою инфраструктуру, а также реализовывать национальную политику и программу развития. Зарубежные туроператоры ожидают создания новых продуктов, связанных с традициями и культурой, а также культурологических туров, пакетов «все включено» и высококлассных гостиниц (4* и $\left.5^{*}\right)$. Должен быть облегчен доступ к природным богатствам за счет усовершенствования транспортной системы (национальной и международной).

Основные маркетинговые усилия должны быть сконцентрированы на обеспечении международного сообщества информацией о стране и ее главных особенностях (на международных форумах, ярмарках и выставках) для улучшения имиджа страны и информирования профессионалов в области международного туризма о возможностях, ожидающих их в стране.

Рост туризма должен произойти преимущественно за счет появления новых посещаемых территорий, поскольку традиционные районы мирового туристского рынка уже достигли предела рекреационной емкости. В связи с этим Казахстан имеет уникальную возможность занять свою нишу на мировом туристском рынке.

\section{Примечания:}

1. Послание Президента Республики Казахстан Н.А. Назарбаева народу Казахстана «Социально-экономическая модернизация - главный вектор развития Казахстана от 27 января 2012 года.

2. Гуляев В.Г. Туризм: экономика и социальное развитие. М., 2003.

3. Агентство по статистике Республики Казахстан. www.stat.kz

4. Нургалиева А.Ш. Оценка конкурентоспособности услуг туристских фирм. Кокшетау, 2004.

5. Токарев Р.Б., Сущность туристской деятельности в регионе. Москва, 1998.

6. Зорин И.В., Квартальнов В.А. Энциклопедия туризма: Справочник. М.: Финансы и статистика, 2000.

7. Ильина Е.Н. Туроперейтинг: организация деятельности: Учебник. М.: Финансы и статистика, 2005.

8. Кабушкин Н.И. Менеджмент туризма: Учебник. М.: Новое знание, 2002.

9. Квартальнов В.А. Туризм: Учебник. М.: Финансы и статистика, 2004.

10. Квартальнов В.А. Теория и практика туризма: Учебник. М.: Финансы и статистика, 2003.

11. Котлер Ф., Боуэн Дж., Мейкенз Дж. Маркетинг. Гостеприимство и туризм: Учебник / Пер. с англ.; Под ред. Р.Д. Ноздревой. М.: ЮНИТИ, 1998.

12. Лесник А.Л. Практика маркетинга в гостиничном и ресторанном бизнесе. М.: Товарищ, 2000.

13. Feizrakhmanova N.M. Major Trends in the Implementation of the System of Decision Making in Tourism Insurance // Tourism Education Studies and Practice, 2014, Vol.(1), No 1, pp. 23-30.

\section{References:}

1. Poslanie Prezidenta Respubliki Kazakhstan N. A. Nazarbaeva narodu Kazakhstana «Sotsial'no-ekonomicheskaya modernizatsiya - glavnyi vektor razvitiya Kazakhstana ot 27 yanvarya 2012 goda. 
2. Gulyaev V.G. Turizm: ekonomika i sotsial'noe razvitie. M.: «Finansy i statistika», 2003.

3. Agentstvo po statistike Respubliki Kazakhstan. www.stat.kz

4. Nurgalieva A.Sh. Otsenka konkurentosposobnosti uslug turistskikh firm. Kokshetau, 2004.

5. Tokarev R.B., Sushchnost' turistskoi deyatel'nosti v regione. Moskva, 1998. 2000

6. Zorin I.V., Kvartal'nov V.A. Entsiklopediya turizma: Spravochnik. M.: Finansy i statistika,

7. Il'ina E.N. Turopereiting: organizatsiya deyatel'nosti: Uchebnik. M.: Finansy i statistika, 2005.

8. Kabushkin N.I. Menedzhment turizma: Uchebnik. M.: Novoe znanie, 2002.

9. Kvartal'nov V.A. Turizm: Uchebnik. M.: Finansy i statistika, 2004.

10. Kvartal'nov V.A. Teoriya i praktika turizma: Uchebnik. M.: Finansy i statistika, 2003.

11. Kotler F., Bouen Dzh., Meikenz Dzh. Marketing. Gostepriimstvo i turizm: Uchebnik / Per. s angl.; Pod red. R.D. Nozdrevoi. M.: YuNITI, 1998.

12. Lesnik A.L. Praktika marketinga v gostinichnom i restorannom biznese. M.: Tovarishch, 2000.

13. Feizrakhmanova N.M. Major Trends in the Implementation of the System of Decision Making in Tourism Insurance // Tourism Education Studies and Practice, 2014, Vol.(1), No 1, pp. 23-30. 